\title{
Mild synthesis of poly(HEMA)-networks as well-defined nanoparticles in supercritical carbon dioxide
}

\author{
R. Pariltia, , D. Alaimo ${ }^{a}$, B. Grignard ${ }^{a}$, F. Boury ${ }^{b}$, S. M. Howdlec, C. Jérômet,a \\ Free-radical dispersion polymerisation of 2-hydroxyethyl methacrylate was carried out in supercritical carbon dioxide (scCO ${ }_{2}$ ) in presence of stabilisers based \\ on polyethylene oxide (PEO) and poly(heptadecafluorodecyl acrylate) (PFDA). Different architectures of copolymer (random, palm-tree and diblock) were \\ tested for their surface tension, cloud point and as a stabilising agent. The diblock architecture was found to be the best candidate resulting into poly (2- \\ hydroxyethyl methacrylate) (poly(HEMA)) spherical particles with the size of $316 \mathrm{~nm}$. Furthermore, the effect of the $\mathrm{CO}_{2}$-phobic block (PEO) in diblock \\ architecture was investigated by using three different chain lenghts $(1000,2000,5000 \mathrm{~g} / \mathrm{mol})$. By optimizing these parameters as well as the reaction \\ conditions, well-defined spherical cross-linked poly(HEMA) particles with a mean diameter of unprecedented low size ( $216 \mathrm{~nm}$ ) have been obtained in mild \\ conditions, i.e. a temperature of $35^{\circ} \mathrm{C}$.
}

\section{Introduction}

Nanoparticles (NPs) of either natural or synthetic polymers have been widely explored for their promising biomedical applications as nano-sized carriers for controlled and targeted delivery of therapeutic agents. They possess unique physical and chemical properties such as high stability, small size, low toxicity and easily tailored chemistry which makes them good candidate for controlled delivery systems. Thus far anticancer drugs, vaccines, and oligonucleotides containing delivery systems have been investigated $^{1}$. These emerging therapies had a major impact in medicine and improved the efficacy of the performance of currently available drugs. ${ }^{1,2}$ Recent studies are focused on designing nanocarriers for controlled release and delivery of protein- or peptidebased therapeutics due to their specific and variety of vital actions in the body. ${ }^{3,4}$ Besides, proteins offer efficient treatments compared to existing therapies such as gene therapy ${ }^{5}$. However, there are several important issues that should be considered regarding proteins; they have a sensitive tertiary structure which is easily degraded by temperature and upon exposure to solvents can lead to the loss of their activity. ${ }^{5,6}$ Therefore different production methods have been investigated in order to preserve the specific structure and activity of proteins 7,8 one

of them being supercritical carbon dioxide $\left(\mathrm{scCO}_{2}\right)$ processes. ${ }^{9}$ Indeed, supercritical carbon dioxide is a cheap solvent with nontoxicity and non-flammability with easily accessible critical point $\left(31.1^{\circ} \mathrm{C}\right.$ and $\left.73.8 \mathrm{bar}\right)$ which makes it also desirable for large-scale productions. ${ }^{10,11}$ Therefore, it has emerged as an alternative medium for conventional solvents due to its environmentally benign properties.

2-hydroxyethyl methacrylate (HEMA) based particles have been reported to exhibit potential applications in the biomedical field. 12,13 Hydrogels of poly(HEMA) present excellent biocompatibility and can act as potential carriers in drug delivery, dental, ophthalmic, and neural tissue engineering applications. ${ }^{14,15}$ Typically, particles based on homo- or copolymers of poly(HEMA) are synthesised in water or water/organic solvent mixtures which necessitates several additional steps for purification and drying of the obtained products. ${ }^{16}$ Furthermore, polymer particles that are produced for pharmaceutical applications face several obstacles, such as the type of solvent that can be used and the level of residual solvent that is permitted in final products. The high affinity of polymers toward organic solvents prohibits complete separation. On the other hand, polymers exhibit inherently low or no solubility in $\mathrm{sCCO}_{2}$ thus making it a very good anti solvent for particle production as well. ${ }^{17}$ Upon depressurization $\mathrm{scCO}_{2}$ goes to gaseous state so that the polymers can be isolated from the reaction media by simple depressurization without solvent residues which allows dry powder formulations that have superior stability when compared to liquid formulations. ${ }^{9}$ Owing to these facts, much more effort has been devoted to use $\mathrm{CO}_{2}$ as a green polymerisation medium and producing particles carrying a therapeutic agent in their core. ${ }^{9}$ It has been reported that a wide range of monomers are soluble in $\mathrm{scCO}_{2}$ whereas their corresponding high molecular-weight polymers are insoluble ${ }^{11}$ except amorphous or low crystalline fluoropolymers ${ }^{13,16,18-25}$, silicones ${ }^{22,26,27}$ and low molar mass polyvinyl alkanoate ${ }^{28-30}$ (poly(vinyl acetate), PVAc and poly(vinyl pivalate, PVPi) that were found to have significant solubility in $\mathrm{scCO}_{2}$ under moderate conditions $\left(<100{ }^{\circ} \mathrm{C},<400 \mathrm{bar}\right)$. Therefore, $\mathrm{scCO}_{2}$ is a good medium to conduct heterogeneous polymerisation processes such as suspension, emulsion and dispersion polymerisation. ${ }^{11}$ Heterogeneous polymerisation techniques led to particle formation with different size and morphologies. ${ }^{31}$ Dispersion polymerisation is defined as a polymerisation in which monomer, initiator and stabiliser are dissolved in the continuous phase acting as a non-solvent for the corresponding polymer ${ }^{32}$, and is especially interesting because it leads to micron sized particles in single batch and many 
commodity polymers can be produced in large scale by this method. ${ }^{33}$ Upon precipitation of the polymer chains, a suitable stabiliser is adsorbed or grafted on the forming particles resulting into long range repulsion between particles and preventing their coagulation. Therefore, a successful dispersion is highly dependent on choosing a ideal stabiliser. ${ }^{34}$

Recently Mc. Allister et. al. have produced well-defined poly(methylmethacrylate) (PMMA) particles in $\mathrm{scCO}_{2}$ by free radical dispersion polymerisation using poly(dimethyl siloxane) end-capped by a methacrylate moiety (PDMS-MA) as a stabiliser. ${ }^{35}$ With such reactive PDMS, they probed the effect of the PDMS-MA concentration ranging from 1-20wt\% on the PMMA particles size. As a rule, increasing the PDMS-MA concentration leads to the decrease of the PMMA particle size from $3.8 \mu \mathrm{m}$ to $0.6 \mu \mathrm{m}$. This effect is attributed to the stabilisation of a larger surface area of formed PMMA at higher PDMS concentration. Thus, a higher number of small PMMA particles can be obtained. Accordingly, the stabiliser concentration is also an important parameter to produce welldefined particles with desired diameter.

In this case, non-crystalline fluorinated-based (co)polymers were found to be very efficient stabilisers for the dispersion polymerisation in $\mathrm{scCO}_{2} \cdot{ }^{13,16,18-25}$ These polymers present unique physico-chemical properties due to their low surface energy, high thermal and chemical stability. ${ }^{36,37}$ As well as their relatively high solubility in $\mathrm{scCO}_{2}$ these polymers have found applications in the dispersion polymerisation of many vinyl monomers such as methacrylate derivatives ${ }^{13,16,38-42}$ (MMA, HEMA, or others methacrylate esters), acrylonitrile ${ }^{20,43}, N$-vinylpyrrolidone ${ }^{25,44}$, styrene ${ }^{22}$ resulting into well-defined spherical particles.

Consequently, we aim to develop a novel dispersion polymerisation process for the one-pot encapsulation of therapeutic proteins in $\mathrm{scCO}_{2}$ which would be highly beneficial both for manufacturing and medical point of view. In a previous study ${ }^{45}$, some of us reported on the synthesis of perfluorinated stabilisers, composed of hydrophilic poly(ethylene oxide) (PEO) and fluorophilic fluorinated acrylate $(1 \mathrm{H}, 1 \mathrm{H}, 2 \mathrm{H}, 2 \mathrm{H}$-heptadecafluorodecyl acrylate, PFDA) sequences combined in different architectures, i.e. random, diblock and palm-tree copolymers and their use as a stabiliser for dispersion polymerisation of HEMA in $\alpha, \alpha, \alpha-$ Trifluorotoluene (TFT). The effect of the stabiliser and monomer concentration were investigated for different architectures of PEO/PFDA copolymers. Stabilisers that were constituted of block architecture, i.e. diblock and palm-tree, reduced the interfacial tension at water/TFT interface significantly compared to the random copolymer. Nevertheless, spherical and monodisperse particles of poly(HEMA) networks have been obtained by dispersion polymerisation regardless of the copolymer architecture of the stabiliser used at $80^{\circ} \mathrm{C}$ degrees in TFT. It has been shown that the size of the particles can be adjusted by changing the stabiliser concentration, so that nanoparticles $(300 \mathrm{~nm})$ could be obtained.

Here, we study these promising perfluorinated copolymers as stabilisers for the synthesis of cross-linked poly(HEMA) nanoparticles in $\mathrm{SCCO}_{2}$ in place of TFT to investigate the feasibility of using this green polymerisation medium. We particularly target and investigate the use of mild conditions of temperature to be compatible with proteins stability, i.e. going down to the body temperature. Therefore, the effect of temperature and pressure on the size, morphology of the particles was investigated as well as the architecture and composition of the stabiliser.

\section{Experimental Part}

\section{Materials}

Poly(ethylene glycol) monomethyl ether (PEO, Fluka, $\mathrm{Mn}=2000 \mathrm{~g} / \mathrm{mol}$ ), Poly(ethylene glycol) monomethyl ether (PEO, Aldrich,

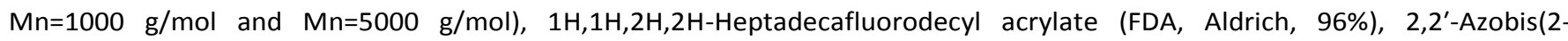
methylpropionitrile) (AIBN, Aldrich, 98\%), S-Dodecyl-S'-( $\alpha, \alpha^{\prime}$-dimethyl- $\alpha^{\prime \prime}$-acetic acid) trithiocarbonate (DDMAT, Aldrich, 98\%), $\alpha, \alpha, \alpha$-Trifluorotoluene (TFT, Aldrich, 99+\%), 1,1,2-trichlorotrifluoroethane (CFC-113, Aldrich, 99.8\%), Deuterated Chloroform $\left(\mathrm{CDCl}_{3}\right.$, Eurisotop, Chloroform D+0.03\% Tetramethylsilane (TMS), >99.8) 2,2'-Azobis(4-methoxy-2,4-dimethylvaleronitrile) (V70,Wako), 2-hydroxyethyl methacrylate (HEMA, Aldrich, 97\%), Ethylene glycol dimethacrylate (EGDMA, Aldrich, 98\%,), Carbon dioxide (15122,CO2 N27 purity > 99,999\%, Air Liquide, Belgium). Ultrapure water was produced by MilliQ plus 188 apparatus (Millipore). The three copolymers exhibiting similar molar mass and composition, i.e. a $\mathrm{PEO}_{45}-b$-PFDA 37 diblock copolymer, a poly((APEO $\left.)_{5}-\mathrm{CO}_{-} \mathrm{FDA}_{46}\right)$ grafted copolymer and a poly(APEO $)_{5}-b-\mathrm{PFDA}_{35}$ palm tree copolymer, were synthesized by RAFT as described previously. ${ }^{45}$

\section{Synthesis of macroRAFT agent (PEO-CTA)}

A conventional synthesis was followed to prepare the macroRAFT agent (PEO-CTA). ${ }^{45}$ It is briefly described below for PEO $2000 \mathrm{~g} / \mathrm{mol}$, the quantities were adjusted for PEO 1000 and $5000 \mathrm{~g} / \mathrm{mol}$. Prior to the reaction, $5 \mathrm{~g}$ of poly (ethylene oxide) (2000 $\mathrm{g} / \mathrm{mol}$ ) was dried 3 times by azeotrope cycles with dry toluene and stored under nitrogen atmosphere. A round-bottom flask was charged with $1.82 \mathrm{~g}$ of RAFT agent S-Dodecyl- $\mathrm{S}^{\prime}$-( $\alpha, \alpha^{\prime}$-dimethyl- $\alpha^{\prime \prime}$-acetic acid)trithiocarbonate (DDMAT) (0.005 mol: $2 \mathrm{eq}$ )), $1.03 \mathrm{~g}$ of $\mathrm{N}, \mathrm{N}^{\prime}$-dicyclohexylcarbodiimide (DCC) (0.005 mol: 2 eq.), $0.06 \mathrm{~g}$ of 4-(dimethylamino)pyridine (DMAP) (0.0005 mol: 0.2 eq.) and $40 \mathrm{ml}$ dry THF. The mixture was then transferred onto dried PEO under nitrogen pressure with the aid of stainless steel capillary. The final mixture was left for stirring at ambient temperature for 120 hours with moderate stirring rate. The macroRAFT agent was 
recovered by precipitation in diethyl ether followed by filtration and drying under vacuum. The macroRAFT agents were analyzed by ${ }^{1} \mathrm{H}-\mathrm{NMR}$ and Size Exclusion Chromatography using dimethyl formamide (DMF) as eluent (SEC-DMF).

\section{Synthesis of diblock stabilisers (PEO-b-PFDA)}

Conventional synthesis of the diblock copolymer was adjusted from previously published method ${ }^{13}$ and extended to 3 different molecular weight macroRAFT agents (PEO-CTA). The procedure and amounts were selected as follows: PEO-CTA (0.537 mmol) was dissolved in $38 \mathrm{~g}$ of TFT in a round-bottom flask. To this solution $19.32 \mathrm{mmol}$ of FDA was added DP $\mathrm{th}_{\mathrm{th}}=(\mathrm{n}([\mathrm{FDA}] /[\mathrm{PEO}-\mathrm{CTA}]=36)$. After the addition of the monomer and a solution of $0.108 \mathrm{mmol}(0.0177 \mathrm{~g})$ AIBN in $2 \mathrm{~g}$ of TFT, the flask was sealed with a 3-way stopcock and subjected nitrogen bubbling in order to eliminate traces of oxygen. Thereafter, the flask was placed in an oil bath at $65^{\circ} \mathrm{C}$ and left for stirring with moderate stirring rate for $48 \mathrm{~h}$. The conversion was determined by ${ }^{1} \mathrm{H}-\mathrm{NMR}$ by taking a crude sample at the end of reaction. Polymerisation ran to full conversion. The polymer was then recovered by precipitation in methanol followed by filtration and drying under vacuum. The resultant diblock copolymers were further characterized by ${ }^{1} \mathrm{H}-\mathrm{NMR}$.

\section{Synthesis of poly (2-hydroxyethyl methacrylate) network nanoparticles in $\mathrm{scCO}_{2}$}

Dispersion polymerisations of 2-hydroxyethyl methacrylate were carried out in a high pressure stainless steel cell (82 $\mathrm{ml}$, ToP Industrie) connected to a syringe pump (ISCO model no. 260D) equipped with a mechanical stirrer, a pressure transducer, a rupture disc, an internal thermocouple, a heating mantel and a digital control unit which enables instant monitoring of the pressure, temperature and stirring rate (Figure S1 and Figure S2).

In a conventional dispersion, the amounts are used as follows: the cell was charged with $8.2 \mathrm{ml}$ of $\mathrm{HEMA}\left(10 \% \mathrm{v} / \mathrm{v} \mathrm{CO}_{2}\right), 82 \mu \mathrm{l}$ of EGDMA (cross-linker, $1 \% \mathrm{v} / \mathrm{v}$ monomer), $0.82 \mathrm{~g}$ of stabiliser (in the case of $10 \% \mathrm{w} / \mathrm{v}$ monomer), $0.1 \mathrm{~g}$ of AIBN (or $0.187 \mathrm{~g} \mathrm{~V}-70,1 \% \mathrm{w} / \mathrm{v}$ monomer). The cell was securely sealed and a small amount of $\mathrm{CO}_{2}$ was introduced. After the heating mantel was clamped, the stirring rate and temperature were set with the control unit. Temperature and pressure were increased step-wise and the reactor was stabilised at the desired conditions. The reaction was run overnight at $400 \mathrm{rpm}$. At the end of the reaction, for the depressurization, initially stirring was stopped and the heating jacket removed and the reactor is allowed to cool down to ambient temperature. Thereafter, the reactor is depressurized gradually by opening an outlet valve. The depressurization rate is not systematically controlled. The pressure release is kept slow enough to avoid particle spraying out or polymer flushing in the outlet pipes. Therefore, the speed can be estimated to be between 5 to 10 bars per minute. After total depressurization, the cell was opened and the product was collected as a dry powder (Figure S3). Obtained products were stored in the ambient temperature in a plastic container.

\section{Characterisations}

${ }^{1} \mathrm{H}$ NMR spectra were recorded with a $400 \mathrm{MHz}$ Brucker spectrometer. ${ }^{1} \mathrm{H}$ NMR spectra of macroinitiator was recorded indeuterated chloroform ( $\left.\mathrm{CDCl}_{3}\right)$ NMR solvent having tetramethysilane (0.03\%TMS) as an internal reference. and for diblock fluorinated copolymers were recorded in 1,1,2-trichlorotrifluoroethane(CFC-113) and $\mathrm{CDCl}_{3}$ mixture. Size exclusion chromatography (SEC) was carried out in DMF (flow rate $1 \mathrm{~mL} / \mathrm{min}$ ) at $40^{\circ} \mathrm{C}$ using a Water 600 autosampler liquid chromatography equipped with a differential refractometer index detector. All the particles were analyzed with scanning electron microscopy (SEM, JEOL JSM 840-A) to evaluate their morphology and average particle sizes. Samples were prepared on SEM stubs and coated with Pt $(30 \mathrm{~nm})$. Average diameter of the particles $\left(D_{n}\right)$ is determined from a conventional SEM images by measuring of randomly selected individual particles with the aid of VistaMetrix software (Version 1.33.0). Coefficient of variance $\left(C_{v}\right)$ is an indicator of size distribution of the particles. It is calculated from the standard deviation $(\sigma)$ divided by the average diameter size $\left(D_{n}\right)$ that is calculated from the SEM images.

$$
\text { Eq. 1: } C_{v}=\left(\sigma / D_{n}\right) * 100
$$

\section{Tensiometry at the water-scCO}

The interfacial tension (Water $/ \mathrm{CO}_{2}$ ) was measured at $30^{\circ} \mathrm{C}$ using a drop tensiometer (Tracker, IT Concept, Longessaigne, France) allowing the determination of the interfacial tension by analysing the axial symmetric shape (Laplacian profile) of the pendant drop of $\mathrm{CO}_{2}$-saturated water in pressurized $\mathrm{CO}_{2}$ (Figure S4). The apparatus consisted of a view cell under $\mathrm{CO}_{2}$ atmosphere, a light source, a CCD camera, a computer, a syringe (Exmire microsyringe MS*GLL100, ITO corporation, Japan), and a motor as described elsewhere by Tewes et al. ${ }^{46}$ Pendant drops were formed at the end of a stainless steel tube, of a 1 mm inside diameter, connected to a syringe. Drop volume and area were controlled during all experiment by a step-by-step motor. Therefore, it was possible to maintain constant the area of the drop during the time of experience, so that the surface tension variation was related only to the adsorption of molecules at the interface. The measurements were performed at $30^{\circ} \mathrm{C}$ and 100 bar, corresponding to a density of $771 \mathrm{~kg} / \mathrm{m}^{3}$. Increasing amounts of copolymer were introduced into the view cell in order to obtain increasing concentrations inside the cell (from $10^{-10}$ to $10^{-4} \mathrm{~mol} / \mathrm{l}$ ). A syringe filled with pure water was coupled to the view cell. Then, the water phase was equilibrated with the $\mathrm{CO}_{2}$ phase for $24 \mathrm{~h}$. Pendant drops whose area is controlled during the whole time of experience by the motor 
were formed at the end of a stainless steel needles (needles 20G, popper, U.S.A.), having an inside diameter of $1 \mathrm{~mm}$ and connected to the syringe.

\section{Cloud point measurements of the diblock copolymers}

The solubility of the statistical/block copolymers indicates their potential to be used as a stabiliser for dispersion polymerisation in $\mathrm{sCCO}_{2}$. Cloud point in $\mathrm{scCO}_{2}$ can be defined as the pressure in which the polymer starts to precipitate out from the solution at a given temperature ${ }^{47}$. Cloud points of synthesised statistical/block copolymers were determined by using high pressure variable volume view cell equipment that was produced by University of Nottingham ${ }^{48}$. The cell supports a maximum pressure of 345 bar. For a typical cloud point measurement $3 \mathrm{~g}\left(15 \% \mathrm{wt}\right.$ monomer/ $\left.\mathrm{CO}_{2}\right)$ of monomer, $150 \mathrm{mg}$ of stabiliser (5\%wt stabiliser/monomer) and $20 \mathrm{~g}$ of $\mathrm{CO}_{2}$ were used. Stabiliser was dissolved in given amount of $\mathrm{CO}_{2}$ was then transferred to the view cell by using a small stainless steel $\mathrm{CO}_{2}$ bomb (Figure S5-A). The weight of the bomb was recorded before and after addition to calculate the exact amount of $\mathrm{CO}_{2}$ in the cell.

The cell was heated up to the desired temperature and allowed to stabilise. Thereafter, the hydraulic piston was slowly moved forward to increase the pressure in the cell until a single phase was observed through the sapphire window (Figure S5-B). At this pressure the light placed at the end of the

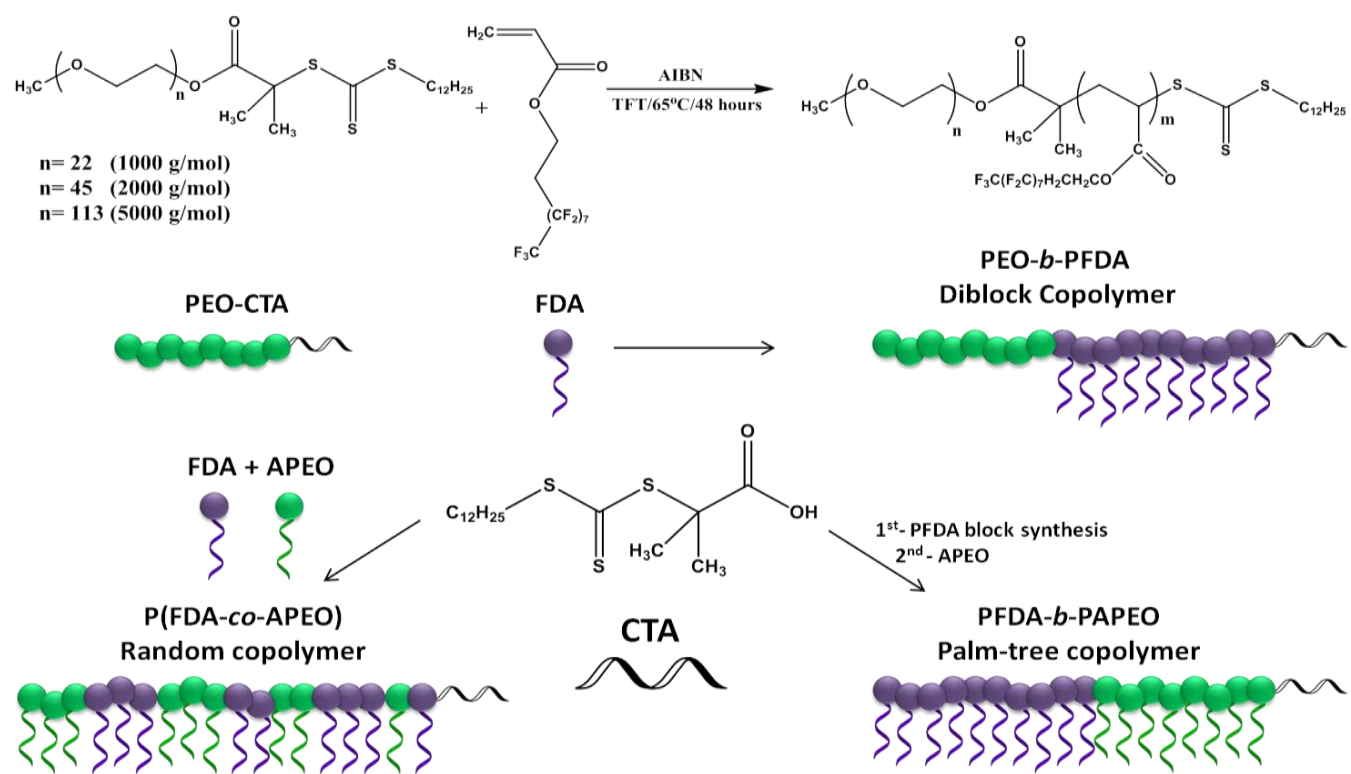

view cell becomes visible. The piston was moved back again slowly to decrease the pressure in a controlled manner to observe the pressure at which the medium is no longer a single phase (Figure S5-C). A cloudy mixture is observed due to precipitation of the polymer from the solution mixture and the light at the back of the view cell is not visible anymore. Cloud points were taken at $35,45,55,65$ and $75{ }^{\circ} \mathrm{C}$ and each point were repeated for 3 times. The cloud points are reported as an average value of these 3 repetitions. 30

\section{Results and discussions}

\section{Synthesis of the stabilisers}

Dispersion polymerisation requires the use of an efficient stabiliser to control the morphology, the size and the stability of the formed particles. In order to investigate both the effect of the architecture and of the composition of the stabilisers on the particles formed in $\mathrm{SCCO}_{2}$, two series of copolymers have been first synthesized.

\section{Stabilisers of different architectures (random, palm-tree and block copolymers)}

The three different copolymers of the same composition and molar mass but having different architecture, i.e. a PEO-b-PFDA diblock copolymers, a P(APEO-co-FDA) random copolymers and a PFDA-b-PAPEO palm tree diblock copolymers (Scheme 1 ) that have already demonstrated their 
efficiency to prepare poly(HEMA) nanoparticles in TFT ${ }^{45}$, were synthesized by RAFT polymerisation to investigate their efficiency as stabilisers for the dispersion polymerisation in $\mathrm{ScCO}_{2}$. Indeed, the fluorinated segments of these copolymers are expected to be $\mathrm{CO}_{2}$-philic while the PEO blocks have

Scheme1: Synthetic approach Synthetic approach to obtain different architectures of fluorinated copolymers as $\mathrm{CO}_{2}$-philic stabiliser via reversible addition-fragmentation chain transfer (RAFT) polymerisation.

Table 1 Characteristics of the synthesized fluorinated copolymers of different architectures with similar composition

\begin{tabular}{|c|c|c|c|c|c|c|}
\hline Entry & Copolymer & $\begin{array}{l}\mathrm{M}_{\mathrm{n}} \mathrm{PEO}^{\mathrm{a}} \\
(\mathrm{g} / \mathrm{mol})\end{array}$ & $\begin{array}{c}\mathrm{M}_{\mathrm{n}} \text { PFDA }^{\mathrm{b}} \\
(\mathrm{g} / \mathrm{mol})\end{array}$ & HFR $^{d}$ & $\begin{array}{c}\text { Mn Total } \\
\text { (g/mol) }\end{array}$ & $\begin{array}{c}\text { Cloud point } \\
\text { (bar) }\end{array}$ \\
\hline 1 & $\mathrm{PEO}_{45}-b-\mathrm{PFDA}_{37}$ & 2000 & 19000 & 1.2 & 21000 & 124 \\
\hline 2 & PFDA $_{35}-b-\mathrm{PA}\left(\mathrm{PEO}_{9}\right)_{5}$ & $2350^{c}$ & 18000 & 1.3 & 20350 & 89 \\
\hline 3 & $\mathrm{P}\left(\mathrm{FDA}_{46}-\mathrm{CO}-\mathrm{A}\left(\mathrm{PEO}_{9}\right)_{5}\right)$ & $2100^{c}$ & 24000 & 1.0 & 26100 & 88 \\
\hline
\end{tabular}

a Experimental molecular weight of PEO calculated by ${ }^{1} \mathrm{H}-\mathrm{NMR}$ spectroscopy, ${ }^{\mathrm{b}}$ Experimental molecular weight of PFDA calculated by ${ }^{1} \mathrm{H}-\mathrm{NMR}$ spectroscopy, $\mathrm{M}_{\mathrm{w}}(\mathrm{FDA})=518$ $\mathrm{g} / \mathrm{mol}^{\mathrm{c}} \mathrm{CM}_{\mathrm{n}} \mathrm{P}(\mathrm{APEO})(\mathrm{APEO}=454 \mathrm{~g} / \mathrm{mol}) ;{ }^{\mathrm{d}} \mathrm{HFR}$ designates Hydrophilic/Fluorinated ratio in the resultant copolymer, ([EO]/[FDA]); ${ }^{\mathrm{e}}$ Minimal solubilisation pressure in CO 2 for a copolymer concentration of $5.10^{-4} \mathrm{~mol} / \mathrm{L}$ at $30^{\circ} \mathrm{C}$.

demonstrated their ability to interact with the poly(HEMA) particles in TFT. The macromolecular characteristics of these three fluorinated copolymers are summarized in Table 1. HFR stands for Hydrophilic/Fluorinated ([EO]/[FDA]) ratio in fluorinated copolymers which is similar to conventional hydrophilic/lipohilic balance (HLB). ${ }^{45}$ The fluorinated segments of these three copolymers of roughly similar compositions, thus similar HFR (1.2 \pm 0.2$)$, are imparting solubility in $\mathrm{scCO}_{2}\left(\mathrm{Table}_{1}\right)$. Quite identical cloud points were measured for the random and palm-tree architectures that are of roughly identical compositions, i.e. they are both copolymers of the same FDA and $\mathrm{A}\left(\mathrm{PEO}_{9}\right)$ (macro)monomers. The diblock copolymer that results from PEO-CTA polymerisation of FDA and thus has only one ester moiety linked to the $\mathrm{PEO}_{45}$ is slightly less soluble in $\mathrm{CO}_{2}$ as depicted by the higher cloud point recorded in the same conditions.

\section{Synthesis of diblock copolymer stabilisers of different compositions}

Once the most suitable architecture was identified, i.e. the PEO-b-PFDA diblock architecture, a series of diblock copolymers of different compositions have been synthesized following the same RAFT polymerisation process but by using PEO based chain transfer agent (PEO-CTA) of three different molecular weights. Commercially available monomethoxy polyethylene glycol (Me-OPEO-OH) of $1000 \mathrm{~g} / \mathrm{mol}, 2000 \mathrm{~g} / \mathrm{mol}$ and $5000 \mathrm{~g} / \mathrm{mol}$ were used for the synthesis of PEO $22-\mathrm{CTA}_{1}$ PEO $45-\mathrm{CTA}_{2}$ and PEO $113-\mathrm{CTA}$, respectively, by adapting the previously reported procedure of Alaimo et. al ${ }^{45}$ (Scheme 1 ). The ${ }^{1} \mathrm{H}-\mathrm{NMR}$ spectra analysis of the macroCTAs allowed us to determine the functionalisation yield of the PEO chain-end by 
comparing the $-\mathrm{CH}_{3}$ end-group of alkyl chain of chain transfer agent (CTA) (Scheme 1) resonating around $\delta=0.87 \mathrm{ppm}$ with the $\mathrm{CH}_{2}$ groups of the PEO repeating units resonating around $\delta=3.6 \mathrm{ppm}$. Functionalisation yields were found to be $82.1 \% 88.3 \%$ and $84.8 \%$ for $\mathrm{PEO}_{22}-\mathrm{CTA}, \mathrm{PEO}_{45}-\mathrm{CTA}$, and $\mathrm{PEO}_{113}-\mathrm{CTA}$, respectively, showing the robustness of the functionalization process which appears equally efficient whatever the molar mass of the PEO at least up to $5000 \mathrm{~g} / \mathrm{mol}$.

The

\begin{tabular}{ccccccc}
\hline Entry & Copolymer & Architecture & HFR $^{\mathrm{a}}$ & $\Delta \gamma^{\mathrm{b}}(\mathrm{mN} / \mathrm{m})$ & $\mathrm{Cs}^{\mathrm{c}}(\mathrm{mol} / \mathrm{L})$ & $\gamma_{\mathrm{f}}{ }^{\mathrm{d}}(\mathrm{mN} / \mathrm{m})$ \\
\hline 1 & $\mathrm{PEO}_{45}-b-\mathrm{PFDA}_{37}$ & Diblock & 1.2 & 13.7 & $1.5510^{-7}$ & 1.2 \\
2 & $\mathrm{PFDA}_{35}-\mathrm{b}-\mathrm{P}\left(\mathrm{APEO}_{9}\right)_{5}$ & Palm tree & 1.3 & 14.4 & $3.1910^{-7}$ & 1 \\
3 & $\mathrm{P}^{-7} \mathrm{FDA}_{46}-\mathrm{CO}-\mathrm{A}\left(\mathrm{PEO}_{9}\right)_{5}$ & Random & 1.0 & 8 & $2.3910^{-7}$ & 6.7 \\
\hline
\end{tabular}

polymerisation of FDA was then performed with the three PEO-CTAs according to previously reported conditions of PEO $45-\mathrm{CTA}^{13}$ and targeting the same polymerisation degree for the PFDA block of all the three resulting diblock copolymers. The diblock copolymers compositions and molecular weight were determined by ${ }^{1} \mathrm{H}-\mathrm{NMR}$ comparing the intensity of PFDA and characteristic peak of $\mathrm{PEO}^{13,45}$. The results are summarized

in Table 3. Since the length of the PEO block varies while the PFDA block is the same, the three diblock stabilisers have a HRF increasing from $\sim 0.6$ to $\sim 3.2$. The fluorinated block being responsible for the solubilisation of the copolymer in $\mathrm{CO}_{2}$, the solubility might be affected by increasing the length of the PEO block. The cloud points of the three diblock copolymers have thus been measured at $35^{\circ} \mathrm{C}$ (Table 2), the minimum temperature targeted for the dispersion synthesis of poly(HEMA) networks. At that temperature, the cloud point of both $\mathrm{PEO}_{22}-b-\mathrm{PFDA}_{38}$ and $\mathrm{PEO}_{45}-b-\mathrm{PFDA}_{37}$ is very similar and slightly lower than the one obtained at $30^{\circ} \mathrm{C}$.

Indeed, decreasing the length of PEO does not constitute a barrier to the dissolution of the PFDA and thus of the stabiliser. In contrast, increasing the length of the PEO to 5000

Table 2 Characteristics of synthesized PEO- $b$-PFDA diblock copolymers

\begin{tabular}{|c|c|c|c|c|c|c|}
\hline Stabiliser & $\mathrm{M}_{\mathrm{n}} \mathrm{PEO}-\mathrm{CTA}(\mathrm{g} / \mathrm{mol})$ & $\mathrm{DP}_{\mathrm{th}^{\mathrm{a}}}$ & HFR $^{b}$ & $\mathrm{M}_{\mathrm{n}} \operatorname{PFDA}^{\mathrm{c}}(\mathrm{g} / \mathrm{mol})$ & $\mathrm{M}_{\mathrm{n}}$ total $(\mathrm{g} / \mathrm{mol})$ & Cloud point ${ }^{d}$ (bar) \\
\hline $\mathrm{PEO}_{22}-b-\mathrm{PFDA}_{38}$ & 1364 & 36 & 0.58 & 19684 & 21048 & 106.8 \\
\hline $\mathrm{PEO}_{45}-b-\mathrm{PFDA}_{37}$ & 2364 & 36 & 1.216 & 19166 & 21530 & 104.9 \\
\hline $\mathrm{PEO}_{113}-b-\mathrm{PFDA}_{38}$ & 5364 & 36 & 3.23 & 19684 & 25048 & ----- \\
\hline
\end{tabular}

Theoretical degree of polymerisation of the PFDA block=(n[FDA]/[PEO-CTA]); ${ }^{b}$ Hydrophilic/Fluorinated ratio of the copolymer=[EO]/[FDA]); ${ }^{c}$ Experimental molecular weight of PFDA block calculated by ${ }^{1} \mathrm{H}-\mathrm{NMR}$ spectroscopy, $\mathrm{M}_{\mathrm{w}}(\mathrm{FDA})=518 \mathrm{~g} / \mathrm{mol}$; ${ }^{\mathrm{d}}$ Minimal solubilisation pressure in $\mathrm{CO}_{2}$ for a copolymer concentration of $(5 \% \mathrm{wt}$ stabiliser/monomer) measured at $35^{\circ} \mathrm{C}$, for $\mathrm{PEO}_{113}-b$-PFDA 38 was found to be insoluble at the view cell pressure limit 345 bar (5000 psi).

Table 3:Water $/ \mathrm{CO}_{2}$ interfacial properties of the three studied copolymers as obtained from the pendant drop tensiometer.

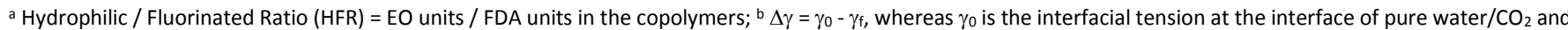
$\gamma_{\mathrm{f}}$ in the resulting surface tension for the highest concentration of copolymer solution; ${ }^{c} C_{S}=$ " saturation concentration " was determined as the intersection of the tangents at high concentration of the sigmoidal plot; ${ }^{\mathrm{d}} \gamma_{\mathrm{f}}=$ Interfacial tension obtained for a copolymer concentration of $10^{-4} \mathrm{~mol} / \mathrm{L}$.

$\mathrm{g} / \mathrm{mol}$ significantly decreases the copolymer solubility, so that the cloud point of the less fluorinated diblock PEO $_{113}-\mathrm{b} \mathrm{PFDA}_{38}$ copolymer could not be measured by our set-up since it remains insoluble at $35^{\circ} \mathrm{C}$ and 345 bar. i.e. the pressure limit of the view cell required for such measurements.

\section{Interfacial tension of random, palm tree and block copolymers at water $/ \mathrm{CO}_{2}$ interface}

The tensioactive properties of the synthesised copolymers with different architectures were studied with pendant drop tensiometer. We have recorded the interfacial tension of the copolymers at the water $/ \mathrm{CO}_{2}$ interface which is an indication of the feasibility of individual architecture to be used in dispersion polymerisation in $\mathrm{scCO}_{2}$. Basically, a known volume of water drop is suspended into the high pressure view cell which was charged with a known concentration of the stabiliser to be measured. The interfacial tension was recorded when the readings reached an equilibrium. The measurements were performed for different stabiliser concentrations ranging from $10^{-10}$ to $10^{-4} \mathrm{~mol} / \mathrm{L}$ at $30^{\circ} \mathrm{C}$ and 100 bar. Figure 1 shows the measured interfacial tension $(\nu$, $\mathrm{mN} / \mathrm{m}$ ) in function of the concentration for the three stabilisers of the same HFR and different architectures (Figure 1). 


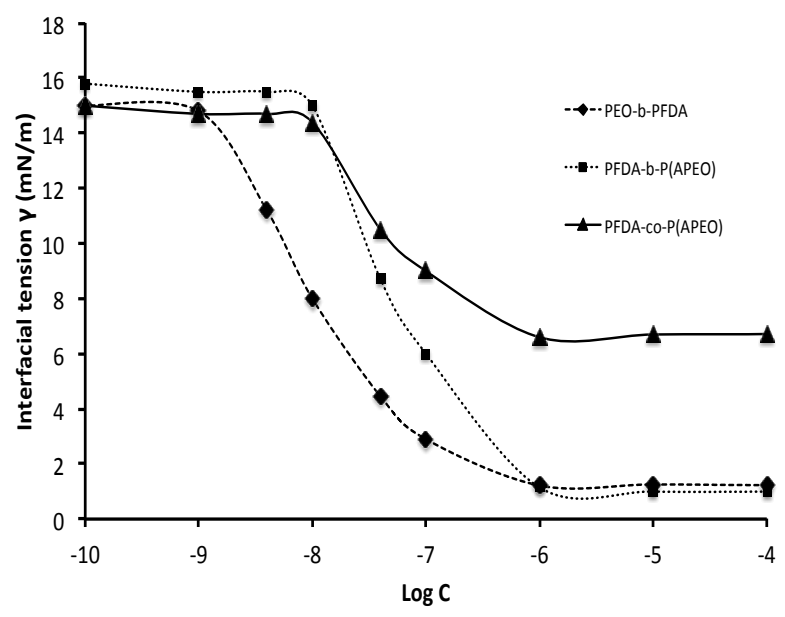

Figure 1 Interfacial tension at the equilibrium yeq $(\mathrm{mN} / \mathrm{m})$ in function of the copolymer concentration $\mathrm{c}(\mathrm{mol} / \mathrm{L})$, at water $/ \mathrm{CO}_{2}$ interface measured at $30^{\circ} \mathrm{C}$ and 100 bar.

As can be seen from the graph, there is a significant decrease in interfacial tension for stabiliser concentrations around $10^{-7}$. This concentration is referred as the saturation concentration which is given by the $\mathrm{Cs}$, and defined as the minimum concentration that leads to maximum decrease in the interfacial tension. The interface is then saturated by the by the stabiliser. For higher stabiliser concentrations than Cs the three curves reach a plateau corresponding to the micelle formation. Data collected from these experimental curves are summarized in the Table 3.

Random, block and palm tree architectures were found to significantly lower the surface tension above $\sim 3.210^{-7} \mathrm{~mol} / \mathrm{L}$. However, palm tree and block copolymers displayed the lowest interfacial tension at the highest used concentration, i.e. $10^{-4} \mathrm{~mol} / \mathrm{L}$. These observations are in good agreement with the interfacial tension data obtained from water/TFT interface. ${ }^{49}$ Thus, the diblock and palm tree architectures appear as better candidates than the random copolymer, to be used as stabiliser for the synthesis of poly(HEMA) particles in $\mathrm{ScCO}_{2}$.

\section{Dispersion polymerisation of 2-hydroxyethyl methacrylate (HEMA) in supercritical carbon dioxide $\left(\mathrm{scCO}_{2}\right)$}

\section{Effect of the stabiliser architecture (random, palm-tree, diblock)}

Considering the high efficiency of the copolymers for stabilising the water $/ \mathrm{CO}_{2}$ interface, the potential of the three copolymers to be used as stabilisers for the dispersion synthesis of poly(HEMA) particles in $\mathrm{scCO}_{2}$ was studied. In order to compare our results with the ones already described by $\mathrm{Ma}$ et. al. ${ }^{13}$, we applied the same experimental conditions, i.e. $10 \mathrm{w} / \mathrm{v} \% \mathrm{HEMA}$ versus $\mathrm{CO}_{2}, 10$ $\mathrm{w} / \mathrm{w} \%$ of stabiliser versus HEMA, $1 \mathrm{w} / \mathrm{w} \%$ of AIBN versus $\mathrm{HEMA}, \mathrm{T}=65^{\circ} \mathrm{C}, \mathrm{P}=385$ bar. After $15 \mathrm{~h}$ of polymerisation and reactor venting, the morphology and size of the collected poly(HEMA) powders were characterized by scanning electron microscopy (SEM) (Figure 2). The results obtained for the three copolymers of various architectures are summarized in Table 4.

As evidenced from the SEM images, well-defined spherical particles of poly(HEMA) were observed with the average diameter size $316 \mathrm{~nm}$ when diblock architecture was used
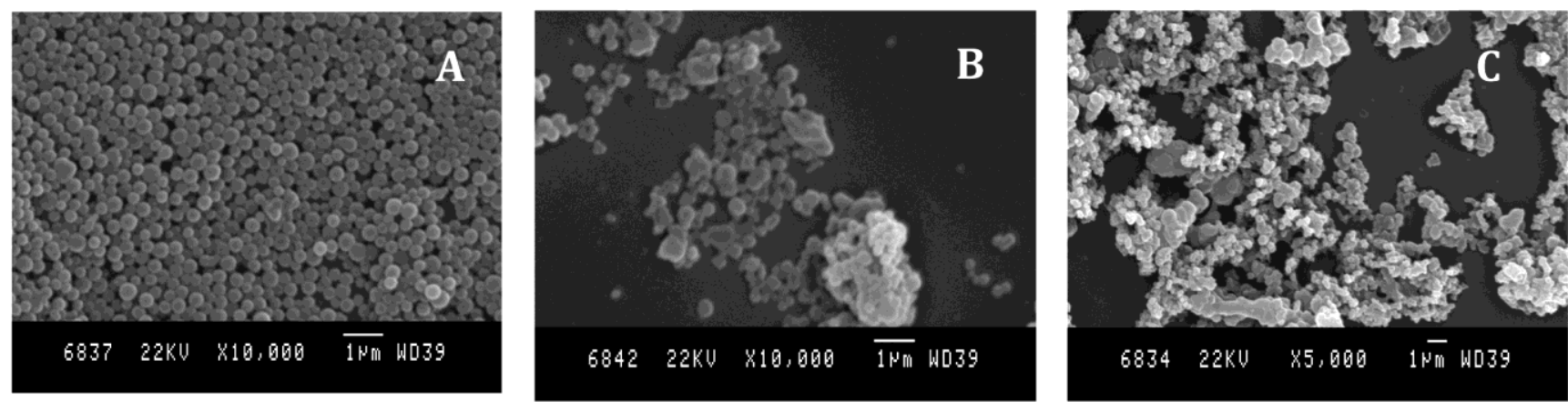
Figure 2-SEM images of Poly(HEMA) collected after polymerisation in $\mathrm{scCO}_{2}$ in presence of A) block stabiliser (table 4, entry A) B) palm tree stabiliser (Table 4 entry B), C) random stabiliser (table 4 entry C).

(Figure 2A). In the case of the other blocky-type structure, i.e. the palm-tree stabiliser (Figure 2B), only a partial stabilisation is obtained with a small portion of particles having a mean size of $350 \mathrm{~nm}$ with a more pronounced aggregation. The random copolymer was the less efficient to stabilise the dispersion of poly(HEMA) in $\mathrm{scCO}_{2}$. Even if the polymerisation is performed in different conditions of pressure and temperature this tendency is in line with the data collected by the water/ $\mathrm{CO}_{2}$ interfacial behaviour. In contrast to our previous study in TFT as a model for $\mathrm{CO}_{2}$, where well-defined particles were observed whatever the stabiliser architecture (all the three copolymer architectures resulted into spherical monodisperse particles between $300-800$ $\mathrm{nm}^{45}$, ill-defined particles are obtained with the random copolymer in $\mathrm{CO}_{2}$ (Figure 2C). These results are however in line with those of Ganapathy et. al ${ }^{16}$ using different composition of amphiphilic steric stabilisers based on $1 H, 1 H, 2 H, 2 H$-perfluorooctyl methacrylate (FOMA), oligoethylene glycol methacrylate (OEGMA), dimethyl amino ethyl methacrylate (DMAEMA) and ethylene oxide (EO). They obtained larger aggregation of particles when they use poly(DMAEMA-Co-FOMA) and poly(OEGMA-Co-FOMA) random stabilisers for dispersion of $\mathrm{HEMA}$ in $\mathrm{ScCO}_{2}$ at similar reaction conditions. On the contrary they obtain particles for the diblock architecture poly(EO-b-PFOMA) $(2 \mathrm{~K} / 20 \mathrm{~K})$ having a size of $500 \mathrm{~nm} .{ }^{16}$ The dispersion in $\mathrm{scCO}_{2}$ is thus found to be more sensitive towards the stabiliser architecture. This could be attributed to the fact that the PEO chain of the diblock stabiliser is more efficiently anchored at the growing poly(HEMA) particles surface whereas the shorter PEO segments of the random and the palm-tree copolymers can only be adsorbed the poly(HEMA) particles/scCO interface leading to less efficient stabilisation. As a consequence, the stabilisation is enhanced for the PEO- $b$-PFDA diblock architecture which appears to be by far the most suitable for giving small $(316 \mathrm{~nm})$ and well-defined particles. In the light of these first results, the diblock architecture was thus selected for investigating the dispersion synthesis of poly(HEMA) networks in milder conditions.

\section{Effects of the temperature and pressure}

Motivated by finding mild conditions to produce poly(HEMA) networks as particles below $300 \mathrm{~nm}$, we firstly studied the possibility to decrease the dispersion polymerisation temperature of a HEMA/bis-acrylate cross-linker mixture, to $35-40^{\circ} \mathrm{C}$. For that purpose, the AIBN free radical initiator was replaced by free-radical initiator 2,2'-Azobis(4-methoxy-2,4-dimethylvaleronitrile) (V-70) that exhibits a lower dissociation temperature. Firstly, we performed dispersions with the PEO $_{45}-b$ - PFDA $_{37}$ stabiliser to make comparative studies while lowering down the starting conditions used above, i.e. $65^{\circ} \mathrm{C}$ and 385 bar.

Initially the pressure was kept constant and the temperature lowered down to $40^{\circ} \mathrm{C}\left(\mathrm{V}-70 / 40^{\circ} \mathrm{C} / 385\right.$ bar) (Table 5 entry $\mathrm{A}$ and Figure 3-A). In these conditions, particles with a mean diameter of $369 \mathrm{~nm}$ and a well-defined spherical morphology have been obtained. Compared to the Figure 2-A, the particle

Table 4 Experimental conditions and particles size obtained for the dispersion polymerisation of $\mathrm{HEMA}$ in $\mathrm{scCO}_{2}$ for the studied different architecture copolymers

\begin{tabular}{cccccc}
\hline Image & Copolymer & Architecture & ${\text { [Monomer }]^{\text {a }}}$ & {$[\text { Stabiliser }]^{\mathrm{b}}$} & $\boldsymbol{D}_{\boldsymbol{n}}{ }^{\mathrm{c}}(\mathbf{n m})$ \\
\hline A & PEO-b-PFDA & Diblock & 10 & 10 & 316 \\
B & PFDA-b-P(APEO) & Palm tree & 10 & 10 & 350 \\
C & PFDA-co-P(APEO) & Random & 10 & 10 & $/$ \\
\hline
\end{tabular}

Conditions: AIBN $1 \mathrm{w} / \mathrm{w} \%$ (with respect to HEMA), $\mathrm{P}=385 \mathrm{bar}, \mathrm{T}=65^{\circ} \mathrm{C}$, stirring rate $=400 \mathrm{rpm}$, reaction time $=15 \mathrm{~h}$. (Conversion $>90 \%$ for each studied system). ${ }^{\mathrm{a}}$ ( $\mathrm{w} / \mathrm{v} \%$ w.r.t $\left.\mathrm{CO}_{2}\right) ;{ }^{b}\left(\mathrm{w} / \mathrm{w} \%\right.$ w.r.t HEMA); ${ }^{\mathrm{c}} \mathrm{D}_{\mathrm{n}} \mathrm{SEM}=$ number average particle diameter determined by measuring the diameter of 100 particles using $\mathrm{SEM}$ images. 

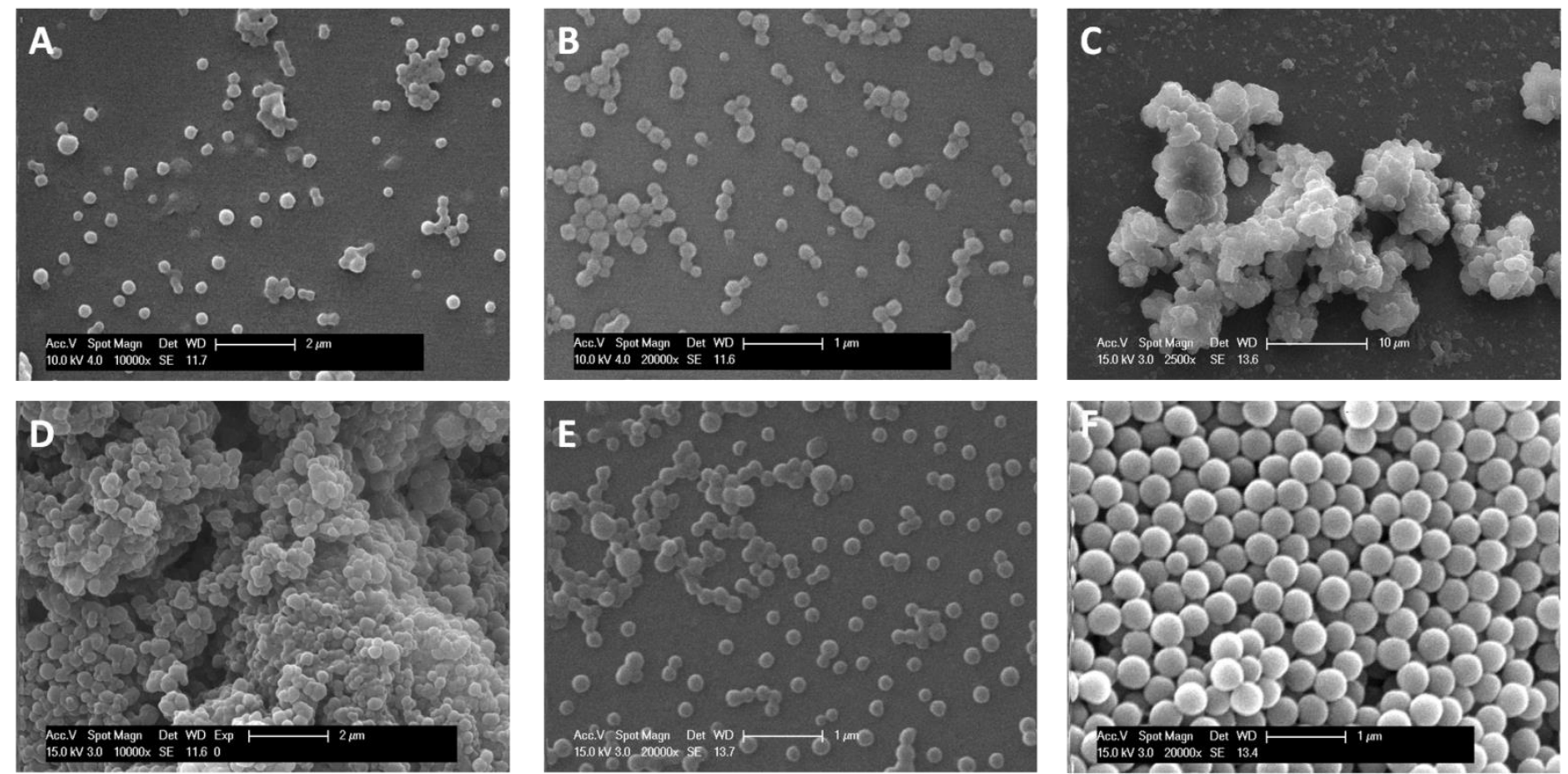

Figure 3:SEM images of collected polyHEMA networks after polymerisation dispersion in $\mathrm{scCO}_{2}$ carried out at A) $40^{\circ} \mathrm{C} / 385$ bar; $\mathrm{B}$ ) $40^{\circ} \mathrm{C} / 300$ bar; $\mathrm{C}$ ) $40^{\circ} \mathrm{C} / 300$ bar, with $5 \%$ $\mathrm{w}_{\text {stabiliser }} / \mathrm{v}_{\text {monomer }}$; D) $35^{\circ} \mathrm{C} / 300$ bar with $\mathrm{PEO}_{22}-\mathrm{b}-\mathrm{PFDA}_{38}$ stabiliser, E) $35^{\circ} \mathrm{C} / 300$ bar with $\left.\mathrm{PEO}_{45}-\mathrm{b}-\mathrm{PFDA}_{37} ;, \mathrm{F}\right) 35^{\circ} \mathrm{C} / 300$ bar with $\mathrm{PEO}_{113}-\mathrm{b}-\mathrm{PFDA} \mathrm{A}_{38}$ stabiliser; for all the polymerisations

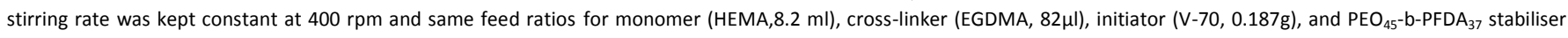
$(0.82 \mathrm{~g})$ were used unless otherwise it is noted (For details see experimental section and Table 5 ).

size has increased from 316 to $369 \mathrm{~nm}$. It should be noted that under a constant pressure of 385 bar, the $\mathrm{CO}_{2}$ density is increased from $864,9 \mathrm{~kg} / \mathrm{m}^{3}$ to $949,7 \mathrm{~kg} / \mathrm{m}^{3}$ by decreasing the temperature from $65^{\circ} \mathrm{C}$ to $40^{\circ} \mathrm{C} 50$. This could modify the solubility of the stabilisers and the surface stabilisation of the growing particles in $\mathrm{CO}_{2}$ therefore resulting into bigger particles ${ }^{39}$.

In order to counter-balance this negative effect on the particles size of increasing the $\mathrm{CO}_{2}$ density resulting of the temperature decrease, the pressure was then decreased to 300 bar keeping constant the temperature at $40^{\circ} \mathrm{C}$ (Table 5 entry $\mathrm{B}$, and Figure 3-B). A significant decrease of the particles size from $316 \mathrm{~nm}$ to $209 \mathrm{~nm}$ was observed leading to one of the smallest particles ever reported for poly(HEMA) dispersion polymerisation in $\mathrm{scCO}_{2}$. This result is in accordance with the study of Shiho et. al ${ }^{39}$ probing the effect of pressure on the poly(HEMA) particle size. They observed a similar increase of the particle size from $370 \mathrm{~nm}$ to $550 \mathrm{~nm}$ by increasing the pressure from 291 bar to 442 bar with PS-b-PFOA diblock copolymers as stabiliser. Another example of such effect was also reported by Canelas et. al. for the synthesis of poly(styrene) particles using a PS- $b$-PDMS stabiliser ${ }^{51}$ in which particle size increased $30 \%$ from $660 \mathrm{~nm}$ to $850 \mathrm{~nm}$ when initial pressure changed from 297 to 439 bar. Dispersion polymerisation of acrylonitrile with PS- $b$-PFOA in $\mathrm{scCO}_{2}$ also showed an increase in the particle size by $60 \%$ from $270 \mathrm{~nm}$ to $430 \mathrm{~nm}$ when the pressure increases from 207 to 444 bar. ${ }^{20}$ Decreasing further the temperature from $40^{\circ} \mathrm{C}$ to $35^{\circ} \mathrm{C}$ at 300 bar (Table 5 , entry $\mathrm{E}$ ) leads to nanoparticles still well below $250 \mathrm{~nm}$ as evidenced by Figure $3-\mathrm{E}$. These results clearly indicate that $35^{\circ} \mathrm{C}$ and 300 bar are very efficient conditions to obtain monodisperse spherical poly(HEMA) particles with remarkably small sizes.

\section{Effect of the stabiliser concentration}

The key-role of the stabiliser has been demonstrated above to obtain well-defined particles which was confirmed by a polymerisation performed in the absence of stabiliser (Figure S6) leading to the recovered ill-defined aggregates of coalesced particles. Nevertheless, minimizing the concentration of stabiliser is of interest in order to limit the fluorinated content engaged in the process and present at the nanoparticles surface in the collected particles. In a previous study Ma et. al. ${ }^{13}$ reported on the synthesis of poly(HEMA) particles having a size of $412 \mathrm{~nm}$ with a $\mathrm{PEO}_{45}-b-\mathrm{PFDA}_{39}$ stabiliser at a concentration as low as $3.5 \% \mathrm{w} / \mathrm{v}$ with respect to $\mathrm{HEMA}$ at $65^{\circ} \mathrm{C}$ and 370 bar. However they obtained $77.4 \%$ yield according to the polymer product they obtained ${ }^{13}$. Therefore, in our mild conditions (at $40^{\circ} \mathrm{C}$ and $300 \mathrm{bar}$ ), we have decreased the stabiliser concentration from $10 \mathrm{wt} \%$ to $5 \mathrm{wt} \%$ (vs. the volume of monomer) for the dispersion polymerisation in order to investigate the impact on the size and the morphology of the nanoparticles. 


\begin{tabular}{|c|c|c|c|c|c|c|}
\hline Image & Stabiliser & Stabiliser (\%) & $\mathrm{T}\left({ }^{\circ} \mathrm{C}\right)$ & P (bar) & $D_{n}{ }^{a}(n m)$ & $\mathrm{C}_{\mathrm{v}}{ }^{\mathrm{b}}(\%)$ \\
\hline A & $\mathrm{PEO}_{45}-b-\mathrm{PFDA}_{37}$ & 10 & 40 & 385 & 369 & 21 \\
\hline B & $\mathrm{PEO}_{45}-b-\mathrm{PFDA}_{37}$ & 10 & 40 & 300 & 209 & 19 \\
\hline $\mathrm{C}$ & $\mathrm{PEO}_{45}-b-\mathrm{PFDA}_{37}$ & 5 & 40 & 300 & Aggregate & \\
\hline $\mathrm{D}$ & $\mathrm{PEO}_{22}-b-\mathrm{PFDA}_{38}$ & 10 & 35 & 300 & Aggregate & \\
\hline The & $\mathrm{PEO}_{45}-b-\mathrm{PFDA}_{37}$ & 10 & 35 & 300 & 216 & 14 \\
\hline $\mathrm{F}$ & PEO $_{113}-b-$ PFDA $_{38}$ & 10 & 35 & 300 & 400 & 8 \\
\hline
\end{tabular}

monomer, cross-linker and initiator concentrations were kept constant for all the dispersions as described in the experimental part. a- number average particle diameter determined by measuring the diameter of 100 particles using SEM images; b Coefficient of variance calculated according to the equation: $\mathrm{Cv}=(\sigma / \mathrm{Dn}) * 100$.

While well-defined and small spherical nanoparticles were obtained in the case of $10 \%$ stabiliser concentration (Figure 3 -B), illdefined aggregates have been obtained at lower stabiliser concentration (Figure $3-\mathrm{C}$ ). In our conditions, $5 \%$ stabiliser concentration is insufficient to obtain well-defined particles.

With another stabiliser, i.e. PS- $b$-PFOA, Shiho et. al investigated the effect of stabiliser concentration on poly(HEMA) particles in $\mathrm{ScCO}_{2}$ (at $65^{\circ} \mathrm{C}$ and $\mathrm{P}=373 \pm 10 \mathrm{bar}$ ) in a range of concentration varying from $6-30 \%$. They also evidenced the formation of large aggregate when the dispersion ran at a stabiliser concentration of $6 \% \mathrm{w} / \mathrm{v}$ with respect to HEMA. ${ }^{39}$

Therefore, to keep discrete spherical particles as free flowing powders by working in the milder reaction conditions developed here as compared to the aforementioned studies a minimum stabiliser concentration of $10 \% \mathrm{w} / \mathrm{v}$ is required.

\section{Effect of the stabiliser composition}

While we were probing the effect of stabiliser architecture, we got some hints on the possible role of the $\mathrm{CO}_{2}$-phobic segmenton the particles stabilisation and morphology. Indeed, even if the diblock and palm-tree stabilisers have a quite similar behaviour at the water $/ \mathrm{CO}_{2}$ interface, their efficiency as stabiliser for poly(HEMA) nanoparticles are quite different, the diblock copolymer being by far the most efficient. Looking at their structure, they rather differ by their $\mathrm{CO}_{2}$-phobic "block", their $\mathrm{CO}_{2}$-philic part being quite similar. Puzzled by this observation, we have investigated the effect of the length of the $\mathrm{CO}_{2}$-phobic block of the diblock copolymer, on the particles size and morphology. For that purpose, we have used the three stabilisers having the same PFDA block but different PEO block length of $\left.1000 \mathrm{~g} / \mathrm{mol}_{(\mathrm{PEO}} 2\right), 2000 \mathrm{~g} / \mathrm{mol}\left(\mathrm{PEO}_{45}\right)$ and $5000 \mathrm{~g} / \mathrm{mol}\left(\mathrm{PEO}_{113}\right)$ (Table 2) for the dispersion polymerisations of $\mathrm{HEMA} / \mathrm{EGDMA}$ at $35^{\circ} \mathrm{C}$ and 300 bar. In contrast to results obtained with the $\mathrm{PEO}_{45}-b-\mathrm{PFDA}_{37}\left(\mathrm{Figure}_{3}-\mathrm{E}\right)$, when the $\mathrm{PEO}_{22}-b$-PFDA 38 is used as stabiliser (Table 5, entry D) irregular shaped aggregates together with only a few amounts (430 mg over approximately 8.2 grams of polymer) of free-flowing powder could be collected (Figure 3-D). Even if the solubility in scCO ${ }_{2}$ is quite similar for these two stabilisers (Table 2-Cloud points), a significant impact of reducing the $\mathrm{CO}_{2}$-phobic block length is observed on the poly(HEMA) stabilisation efficiency. When the block is not long enough, the stabiliser lacks efficiency which is in line with the palm-tree/diblock stabilisers comparison. In case of the $\mathrm{PEO}_{113}-b$ - PFDA 38 (Table 5, entry F) highly monodisperse welldefined nanoparticles are obtained (Figure 3-F) which are however larger (diameter $400 \mathrm{~nm}$ ) as compared to PEO $45-b$-PFDA 37 . These results highlight the significant role of the $\mathrm{CO}_{2}$-phobic block when designing an efficient stabiliser for $\mathrm{scCO}_{2}$. In our study, a block length of $2000 \mathrm{~g} / \mathrm{mol}$ for PEO appears as optimal to get poly(HEMA) networks with a size close to $200 \mathrm{~nm}$.

\section{Conclusions}

The synthesis of poly(HEMA) nanoparticles was successfully performed in $\mathrm{scCO}_{2}$ by using different architectures of amphiphilic copolymers based on PEO and PFDA. The results indicated that the diblock architecture is by far the best candidate to stabilise HEMA in supercritical carbon dioxide. Discrete spherical poly(HEMA) networks were obtained with the lowest size of $209 \mathrm{~nm}$. To the best of our knowledge, herein the mildest synthesis conditions were reported for the synthesis of the poly(HEMA) particles in $\mathrm{scCO}_{2}$ which leads to monodisperse particles having size of $216 \mathrm{~nm}$. The size of the particles can be controlled by the temperature, pressure and the composition of the amphiphilic block copolymer. We believe that this will pave the way for incorporation of temperature and solvent sensitive therapeutic agents. Thus, they can be introduced to the reaction mixture from the beginning for in-situ encapsulation. One-pot synthesis of loaded particles will be the highlight of our future work.

\section{Acknowledgements}

Authors thank for the European financial support in the frame of the NanoFar program, an Erasmus Mundus Joint Doctorate (EMJD) program in nanomedicine and pharmaceutical innovation. CERM is indebted to Interuniversity Attraction Poles (IAP-7/5-FS2). 


\section{References}

R. Chouhan and A. K. Bajpai, J. Mater. Sci. Mater. Med., 2009, 20, 1103-1114.

Y. Malam, M. Loizidou and A. M. Seifalian, Trends Pharmacol. Sci., 2009, 30, 592-599.

M. L. Tan, P. F. M. Choong and C. R. Dass, Peptides, 2010, 31, 184-193.

S. Mura, J. Nicolas and P. Couvreur, Nat. Mater., 2013, 12, 991-1003.

Z. Gu, A. Biswas, M. Zhao and Y. Tang, Chem. Soc. Rev., 2011, 40, 3638-55.

M. J. Whitaker, J. Hao, O. R. Davies, G. Serhatkulu, S. Stolnik-Trenkic, S. M. Howdle and K. M. Shakesheff, Journal of Controlled Release, 2005, vol. 101, pp. 85-92.

D. M. Cook, B. M. K. Biller, M. L. Vance, a. R. Hoffman, L. S. Phillips, K. M. Ford, D. P. Benziger, A. Illeperuma, S. L. Blethen, K. M. Attie, L. N. Dao, J. D. Reimann and P. J. Fielder, J. Clin. Endocrinol. Metab., 2002, 87, 4508-4514.

W. S. Choi, G. G. Murthy, D. A. Edwards, R. Langer and A. M. Klibanov, Proc. Natl. Acad. Sci. U. S. A., 2001, 98, $11103-11107$.

S. P. Cape, J. A. Villa, E. T. S. Huang, T. Yang, J. F. Carpenter and R. E. Sievers, Pharmaceutical Research, $2008,25$.

J. L. Kendall, D. a. Canelas, J. L. Young and J. M. DeSimone, Chem. Rev., 1999, 99, 543-564.

A. I. Cooper, J. Mater. Chem., 2000, 10, 207-234.

R. Filmon, F. Grizon, M. F. Baslé and D. Chappaard, Biomaterials, 2002, 23, 3053-9.

Z. Ma and P. Lacroix-desmazes, Polymer, 2004, 45, 6789-6797.

A. J. Cadotte and T. B. Demarse, J. Neural Eng., 2005, 2, 114-122.

S. Abraham, S. Brahim, K. Ishihara and A. Guiseppi-Elie, Biomaterials, 2005, 26, 4767-4778.

H. S. Ganapathy, H. S. Hwang, M. Y. Lee, Y. T. Jeong, Y. S. Gal and K. T. Lim, J. Mater. Sci., 2008, 43, 2300-2306.

S.-D. Yeo and E. Kiran, J. Supercrit. Fluids, 2005, 34, 287-308.

J. M. DeSimone, Science, 2002, 297, 799-803.

C. Lepilleur and E. J. Beckman, Macromolecules, 1997, 9297, 745-756.

H. Shiho and J. M. DeSimone, Macromolecules, 2000, 33, 1565-1569.

P. Christian, M. R. Giles, R. M. T. Griffiths, D. J. Irvine, R. C. Major and S. M. Howdle, Macromolecules, 2000, 9222-9227.

N. Baran, S. Deniz, M. Akgün, I. N. Uzun and S. Dinçer, Eur. Polym. J., 2005, 41, 1159-1167.

H. Yuvaraj, H. S. Hwang, M. H. Woo, E. J. Park, H. S. Ganapathy, Y. S. Gal and K. T. Lim, J. Supercrit. Fluids, 2007, 42, $359-365$.

M. R. Giles, R. M. T. Griffiths, A. Aguiar-Ricardo, M. M. C. G. Silva and S. M. Howdle, Macromolecules, 2001, 34, $20-25$.

T. Carson, J. Lizotte and J. M. Desimone,Macromolecules, 2000, 33, 15-18.

A. Galia, A. Giaconia, V. laia and G. Filardo, J. Polym. Sci. Part A Polym. Chem., 2004, 42, 173-185.

K. S. Oh, W. Bae and H. Kim, Eur. Polym. J., 2008, 44, 415-425.

H. Lee, E. Terry, M. Zong, N. Arrowsmith, S. Perrier, K. J. Thurecht and S. M. Howdle, J. Am. Chem. Soc., 2008, 130, $12242-3$.

E. J. Park, A. P. Richez, N. A. Birkin, H. Lee, N. Arrowsmith, K. J. Thurecht and S. M. Howdle, Polymer (Guildf)., 2011, 52, 5403-5409.

N. A. Birkin, N. J. Arrowsmith, E. J. Park, A. P. Richez and S. M. Howdle, Polym. Chem., 2011, 2, 1293.

R. Arshady, Colloid Polym. Sci., 1992, 270, 717-732.

S. Slomkowski, J. V. Alemán, R. G. Gilbert, M. Hess, K. Horie, R. G. Jones, P. Kubisa, I. Meisel, W. Mormann, S. Penczek and R. F. T. Stepto, Pure Appl. Chem., 2011, 83, 2229-2259.

A. A. A. Albertsson, K. D. W. H. De Jeu, H. K. S. Kobayashi, K. L. L. Leibler, T. E. L. I. Manners, M. M. E. M. Terentjev, M. V. B. Voit and G. W. U. Wiesner, Advances in Polymer Science Editorial Board :, 2009.

C. Boyère, C. Jérôme and A. Debuigne, Eur. Polym. J., 2014, 61, 45-63.

T. D. McAllister, L. D. Farrand and S. M. Howdle, Macromol. Chem. Phys., 2016, 1-8.

T. Imae, Curr. Opin. Colloid Interface Sci., 2003, 8, 307-314.

S. C. Sharma, D. P. Acharya, M. García-Roman, Y. Itami and H. Kunieda, Colloids Surfaces A Physicochem. Eng. Asp., 2006, 280, 140145.

H. Shiho and J. M. DeSimone, Macromolecules, 2001, 34, 1198-1203.

H. Shiho and J. M. DeSimone, J. Polym. Sci., Part A Polym. Chem., 2000, 38, 3783-3790.

W. Wang, M.R. Giles, D. Bratton, D. J. Irvine,S.P. Armes, V.W. Weaver and S.M. Howdle, Polymer, 2003,44,3803-3809.

H. M. Woods, C. Nouvel, P. Licence, D. J. Irvine and S. M. Howdle, Macromolecules, 2005, 3271-3282.

M. Zong, K. J. Thurecht and S. M. Howdle, Chem. Commun.,2008, 5942-5944.

Z. Wang, Y. Jun, Q. Dong, T. Liu and C. Pu, Polymer,2006, 47, 7670-7679.

T. Berger, B. McGhee, U. Scherf and W. Steffen, Macromolecules, 2000, 33, 3505-3507.

D. Alaimo, A. Beigbeder, P. Dubois, G. Broze, C. Jérômeand B. Grignard, Polym. Chem.2014, 5273-5282.

F. Tewes and F. Boury, J Phys. Chem. B, 2004,108, 2405-2412.

B. Tan, H. M. Woods, P. Licence, S. M. Howdle and A. I. Cooper,Macromolecules, 2005, 1691-1698.

P. Licence, M. P. Dellar, R. G. M. Wilson, P. A. Fields, D. Litchfield, H. M. Woods, M. Poliakoff and S. M. Howdle, Rev. Sci. Instrum., 2004, 75, 3233-3236.

D. Alaimo, D. Hermida Merino, B. Grignard, W. Bras, C. Jérôme, A. Debuigne and C. J. Gommes, J. Phys. Chem. B, 2015, 119, 1706- 
1716.

50 M. McHugh and V. Krukonis, Supercrit. Fluid Extr. - Princ. Pract., 1994, 99-134.

51 D. A. Canelas and J. M. DeSimone, Macromolecules, 1997, 30, 5673-5682. 